\title{
Ifosfamide Encephalopathy and Nonconvulsive Status Epilepticus
}

\author{
Alberto Primavera, Daniela Audenino, Leonardo Cocito
}

\begin{abstract}
Background: Ifosfamide (IFX), an alkylating agent and isomer of cyclophosphamide, is used as a single agent or a component of multi-agent chemotherapy in the treatment of ovarian, testicular, head and neck cancers, sarcomas and lymphomas. Encephalopathy is manifested by cerebellar ataxia, confusional state, complex visual hallucinations, extrapyramidal signs, seizures, and mutism. Case reports: We report two patients with non-Hodgkin's lymphoma presenting with mutism and confusional state after IFX infusion. Nonconvulsive status epilepticus (NCSE) as the cause of confusion was diagnosed on the basis of EEG pattern and the apparent improvement following intravenous administration of diazepam. Conclusions: Electroencephalogram abnormalities during IFX treatment have been described but recordings are only available in six cases. In three of them, paroxysmal alterations warranted the diagnosis of NCSE; however, most cases of IFX encephalopathy might have associated NCSE.
\end{abstract}

RÉSUMÉ: L'encéphalopathie à l'ifosfamide et le status epilepticus non convulsif. Introduction: L'ifosfamide (IFX), un agent alkylant isomère de la cyclophosphamide, est utilisé en monothérapie ou en thérapie combinée en chimiothérapie du cancer de l'ovaire, du testicule, de la tête et du cou, de sarcomes et de lymphomes. L'encéphalopathie se manifeste par une ataxie cérébelleuse, un état confusionnel, des hallucinations visuelles complexes, des signes extrapyramidaux, des crises convulsives et du mutisme. Observation: Nous rapportons le cas de deux patients atteints de lymphomes non hodgkiniens, qui ont présenté du mutisme et un état confusionnel après une infusion de IFX. Le diagnostic de status epilepticus non convulsif (SÉNC) comme étiologie de la confusion a été posé en se basant sur le tracé ÉEG et l'amélioration suite à l'administration intraveineuse de diazépam. Conclusions: Des anomalies ÉEG pendant le traitement à l'IFX ont été décrites, mais les tracés ne sont disponibles que dans six cas. Dans trois de ces cas, des altérations paroxystiques ont justifié le diagnostic de SÉNC. Cependant, la plupart des cas d'encéphalopathie à l'IFX pourraient être associés à un SÉNC.

Can. J. Neurol. Sci. 2002; 29: 180-183

Ifosfamide (IFX), an alkylating agent and cyclophosphamide isomer, is used as a single agent or as a component of multi-agent chemotherapy to treat a broad range of tumors including ovarian, testicular, head and neck cancers, sarcomas and lymphomas. Ifosfamide and its metabolites penetrate the blood barrier well after systemic administration, with CNS toxicity occurring in 10$40 \%$ of patients receiving high doses of the drug. ${ }^{1}$ Encephalopathy is manifested by cerebellar ataxia, mental confusion, complex visual hallucinations, extrapyramidal signs, seizures, mutism, and sometimes coma. ${ }^{1-4}$ The disorder usually begins within 24 hours after the drug infusion but it may be delayed by four to six days., ${ }^{2,3}$ The encephalopathy is generally reversible after withdrawal of the drug but persistent symptoms, or even fatality, may occur. Three patients with IFX-induced nonconvulsive status epilepticus (NCSE) have recently been reported. ${ }^{5-7}$ We observed two patients with lymphoma who developed mutism and confusion after IFX infusion, and whose EEG patterns were suggestive of NCSE.

\section{Case Reports}

\section{Patient No 1.}

A 27-year-old woman presented with sudden impairment of spontaneous speech with verbal perseveration and monosyllabic answers followed by mental confusion while hospitalized in the internal medicine department of Genoa University. Past medical history was negative for both cerebrovascular disease and seizures. She had been diagnosed as having Burkitt's lymphoma, stage IV, one year before (with

From the Department of Neurological Sciences and Vision, University of Genova, Genova, Italy.

RECEIVED APRIL 17, 2001. ACCEPTED IN FINAL FORM OCTOBER 15, 2001. Reprint requests to: Leonardo Cocito, Dipartimento di Scienze Neurologiche e della Visione, Via De Toni 5, I-16132 Genova, Italy. 


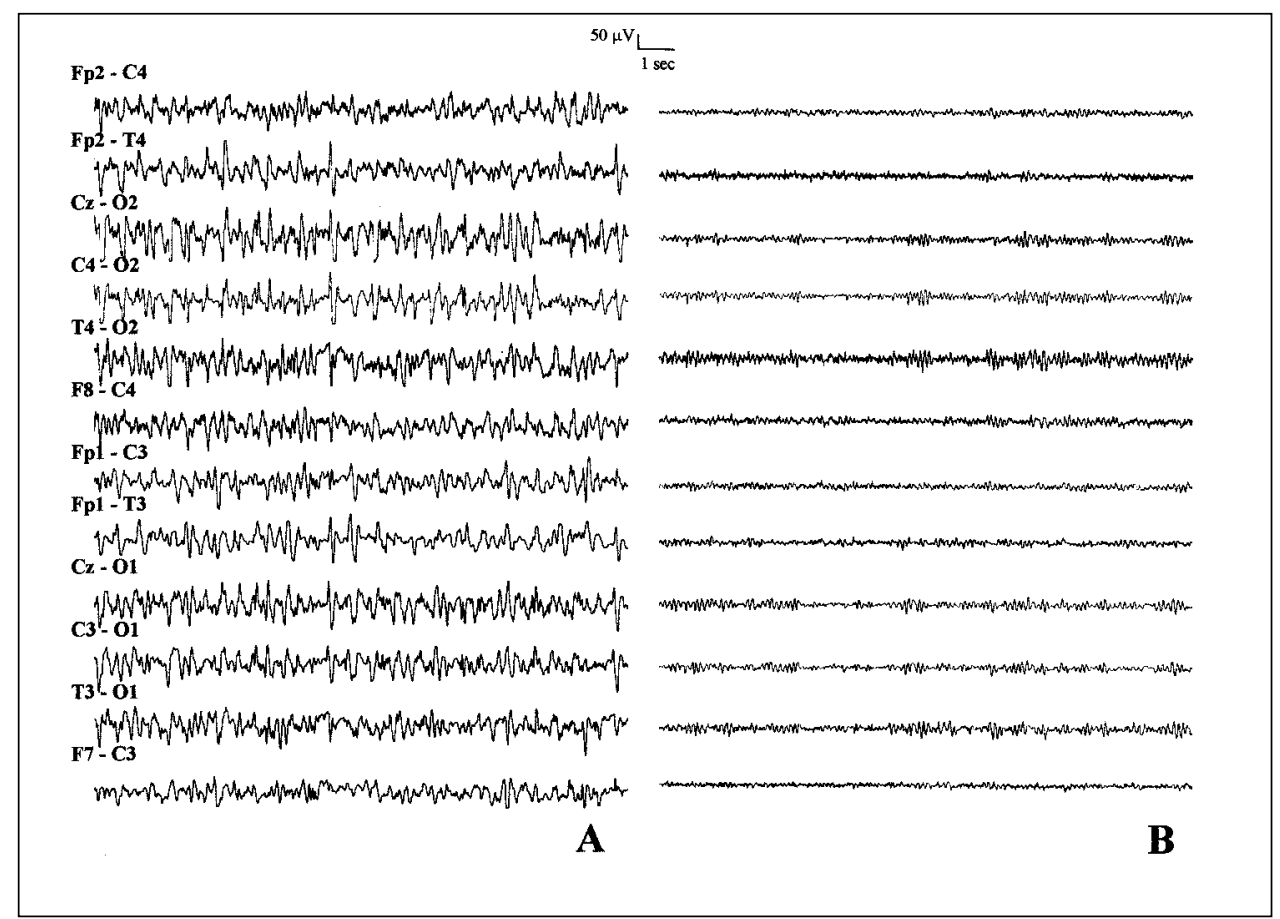

Figure 1: Patient No 2, A: EEG recorded during the acute phase showing a continuous generalized medium- to high-amplitude (100-200 $\mu \mathrm{V}, 1-1.5 \mathrm{~Hz}$ ) activity of spike and wave, and sharp-and slow-wave complexes. B: EEG following intravenous diazepam $5 \mathrm{mg}$, showing a transient suppression of the paroxysmal abnormalities (Filter settings: LFF $0.3 \mathrm{~Hz}$; HFF $70 \mathrm{~Hz}$ ).

CT evidence of a mediastinal mass) and underwent chemotherapy with adriamycin, vincristine, prednisone, melphalan, and methotrexate. Some days prior to the admission she presented with dyspnea, cough and fever. Chest and abdomen CT scan showed a recurrence of the tumor. Laboratory investigation indicated creatinine $130 \mu \mathrm{mol} / \mathrm{l}$, and LDH 2611 $\mathrm{U} / \mathrm{dl}$. A five-day chemotherapy protocol was started, consisting of IFX $\left(2.5 \mathrm{~g} / \mathrm{m}^{2}\right.$, intravenously over one hour), mesna $\left(800 \mathrm{mg} / \mathrm{m}^{2}\right.$ in four divided doses), epirubicin (50 mg/m² over 30 minutes, only on the first day), followed by etoposide $100 \mathrm{mg} / \mathrm{m}^{2} \mathrm{IV}$ over one hour. On the second day she became poorly responsive with a decrease in arousal progressing to somnolence. If verbally stimulated, she was mute or exhibited perseveration and echolalia; orientation and memory could not be tested. The neurological examination revealed no localizing signs, plantar reflexes were flexor bilaterally and signs of meningeal irritation were absent. Serum electrolytes, urea, and creatinine were not different from baseline, and brain CT scan was normal. An EEG revealed diffuse continuous generalized medium to high amplitude spike and wave and sharp and slow-wave complexes, 1.5 to $2 \mathrm{~Hz}$, consistent with the diagnosis of NCSE. Since the possibility of IFX-induced neurotoxicity was considered, chemotherapy was discontinued and low doses of diazepam ( $2 \mathrm{mg} \mathrm{IV}$, followed by oral $2 \mathrm{mg}$ tid) were given. The neurological status improved and returned to baseline conditions within 48 hours. A repeat EEG 24 hours after onset showed diffuse slowing of electric activity while a further EEG four days later was normal. One month later she received another course of IFX associated with oral methylene-blue, and no symptoms of neurotoxicity occurred.

\section{Patient No 2.}

A 57-year-old woman was seen by the neurological consultant due to confusional state and mutism associated with high fever, presenting 48 hours after IFX chemotherapy. One year before she had been diagnosed as having Burkitt's lymphoma (bulky stage IV disease with involvement of lung, kidney, pancreas, adrenal gland and retroperitoneal lymph nodes). At the time she underwent both chemotherapy regimens of Magrath protocol. ${ }^{8}$ During the CODOX-M regimen (which included cyclophosphamide, vincristine, doxorubicin, cytarabine and methotrexate), she developed paresthesias, possibly related to vincristine neurotoxicity. Forty-eight hours after starting the IVAC regimen (a fiveday protocol including intravenous IFX $1500 \mathrm{mg} / \mathrm{m}^{2}$ over one hour, seven doses of mesna $360 \mathrm{mg} / \mathrm{m}^{2}$ and etoposide $60 \mathrm{mg} / \mathrm{m}^{2}$, plus cytarabine $2 \mathrm{mg} / \mathrm{m}^{2}$ on days 1 and 2 , and methotrexate $12 \mathrm{mg}$ on day 5), she presented with memory impairment and urinary incontinence. These symptoms were soon followed by unresponsiveness to verbal command, absence of spontaneous speech and echolalia which lasted for three days. Serum electrolytes, urea, creatinine concentration, and brain CT scan were normal. Electroencephalogram was not performed at the time.

When evaluated by neurological consultation on this occasion, one year after initial therapy, she had been rehospitalized due to CT evidence of abdominal recurrence of the tumor. A second IVAC chemotherapy regimen was started. On the third day she presented with a confusional state. Though apparently alert and attentive, she answered questions with single words and exhibited frequent perseveration and echolalia. The remaining neurological findings indicated only mild extrapyramidal 
Table: Ifosfamide and NCSE: a review of literature

\begin{tabular}{lccccccc}
\hline $\begin{array}{l}\text { Authors } \\
\text { (reference) }\end{array}$ & $\begin{array}{c}\text { Age/ } \\
\text { Gender }\end{array}$ & $\begin{array}{c}\text { Underlying } \\
\text { disease }\end{array}$ & $\begin{array}{c}\text { Dose Time of onset } \\
\text { of IFX }\end{array}$ & $\begin{array}{c}\text { Main clinical } \\
\text { features IFX) }\end{array}$ & $\begin{array}{c}\text { Delay to } \\
\text { diagnosis of } \\
\text { encephalopathy }\end{array}$ & $\begin{array}{c}\text { EEG findings and } \\
\text { acute treatment }\end{array}$ & $\begin{array}{c}\text { Duration Diagnosis } \\
\text { of the } \\
\text { of NCSE }\end{array}$ \\
& & & &
\end{tabular}

\begin{tabular}{|c|c|c|c|c|c|c|c|c|}
\hline $\begin{array}{l}\text { Wengs } \\
\text { et al,19935 }\end{array}$ & $57 / F$ & $\begin{array}{l}\text { Malignant mixed } \\
\text { mesodermal tumor } \\
\text { of uterus }\end{array}$ & $\begin{array}{l}2 \mathrm{~g} / \mathrm{m}^{2} \\
4 \text { days }\end{array}$ & $12 \mathrm{~h}$ & $\begin{array}{c}\text { Perseveration, echolalia, } \\
\text { bilateral synchronous } \\
\text { myoclonus }\end{array}$ & $2 \mathrm{~h}$ & $\begin{array}{l}\text { Diffuse slowing with } \\
\text { superimposed, posteriorly } \\
\text { predominant triphasic } \\
\text { complexes. Improvement after } \\
\quad 3 \mathrm{mg} \text { diazepam }\end{array}$ & Few hours \\
\hline
\end{tabular}

\begin{tabular}{|c|c|c|c|c|c|c|c|c|c|}
\hline $\begin{array}{l}\text { Bhardwaj } \\
\text { and Badesha } \\
1995^{6}\end{array}$ & $71 / \mathrm{F}$ & $\begin{array}{l}\text { Malignant mixed } \\
\text { mesodermal tumor } \\
\text { of uterus }\end{array}$ & $\begin{array}{l}1.5 \mathrm{~g} / \mathrm{m}^{2} \\
5 \text {-days }\end{array}$ & $60 \mathrm{~h}$ & $\begin{array}{l}\text { Unresponsiveness to } \\
\text { verbal commands }\end{array}$ & $24 \mathrm{~h}$ & $\begin{array}{l}\text { Continuous generalised medium- } \\
\text { to high-amplitude spike and wave, } \\
\text { and sharp- and slow-wave } \\
\text { complexes }(1 \mathrm{~Hz})\end{array}$ & $24 \mathrm{~h}$ & Yes \\
\hline $\begin{array}{l}\text { Kaplan } \\
\text { et al,1996 }\end{array}$ & $22 / M$ & $\begin{array}{l}\text { Non-Hodgkin } \\
\text { lymphoma }\end{array}$ & not available & $12 \mathrm{~h}$ & $\begin{array}{l}\text { Lethargy, mutism, } \\
\text { staring gaze }\end{array}$ & $24 \mathrm{~h}$ & $\begin{array}{l}\text { EEG improvement } 5 \text { min } \\
\text { after iv lorazepam administration }\end{array}$ & Few hours & Yes \\
\hline $\begin{array}{l}\text { Danesh } \\
\text { et al,1989 }\end{array}$ & $64 / F$ & $\begin{array}{l}\text { Metastatic } \\
\text { endometrial } \\
\text { sarcoma }\end{array}$ & $\begin{array}{l}2 \mathrm{~g} / \mathrm{m}^{2} \\
5 \text { days }\end{array}$ & $50 \mathrm{~h}$ & $\begin{array}{l}\text { Confusion, mutism, } \\
\text { lethargy, twitching of the } \\
\text { mouth and neck }\end{array}$ & $24 \mathrm{~h}$ & $\begin{array}{l}\text { Nearly continuous high- } \\
\text { amplitude frontally dominant } \\
\text { triphasic waves }\end{array}$ & Few days & No \\
\hline $\begin{array}{l}\text { Simonian } \\
\text { et al, } 1993^{9}\end{array}$ & $59 / \mathrm{F}$ & $\begin{array}{l}\text { Stage IV ovarian } \\
\text { adenocarcinoma }\end{array}$ & $\begin{array}{c}1.7 \mathrm{~g} / \mathrm{m}^{2} \\
3 \text { days }\end{array}$ & $48 \mathrm{~h}$ & $\begin{array}{l}\text { Confusion, stupor, mutism, } \\
\text { transient left gaze preference } \\
\text { and left lip-twitching }\end{array}$ & $6 \mathrm{~h}$ & $\begin{array}{l}\text { Continuous, generalized, } \\
\text { irregular slowing with admixed } \\
\text { sharp activity. Improvement } \\
\text { after } 5 \mathrm{mg} \text { diazepam }\end{array}$ & $10 \mathrm{~h}$ & No \\
\hline $\begin{array}{l}\text { Simonian } \\
\text { et al, } 1993^{9}\end{array}$ & $32 / \mathrm{F}$ & $\begin{array}{l}\text { Stage IV ovarian } \\
\text { adenocarcinoma }\end{array}$ & $\begin{array}{l}1.7 \mathrm{~g} / \mathrm{m}^{2} \\
3 \text { days }\end{array}$ & $48 \mathrm{~h}$ & Catatonia, mutism & $24 \mathrm{~h}$ & $\begin{array}{l}\text { Continuous, generalized, } \\
\text { irregular slow activity with } \\
\text { admixed sharp activity. } \\
\text { Improvement after } 5 \text { mg diazepam }\end{array}$ & $24 \mathrm{~h}$ & No \\
\hline
\end{tabular}

signs. Electrolytes, urea and creatinine were normal. An EEG revealed continuous generalized medium- to high-amplitude (100-200 $\mu \mathrm{V}, 1-1.5$ $\mathrm{Hz}$ ) spike and wave, and sharp- and slow-wave complexes (Figure 1A), pointing to a diagnosis of NCSE; the intravenous administration of $5 \mathrm{mg}$ diazepam transiently suppressed the paroxysmal EEG abnormalities (Figure 1B), though the effect lasted only 10 minutes. An oral treatment of diazepam ( $2 \mathrm{mg}$ tid) was started. Neurological status improved within 24 hours and a repeat EEG three days later was normal. A repeat CT scan of the brain showed small cerebellar and capsular hypodensities likely representing lacunar ischemic lesions unrelated to the clinical picture. She died a month later due to the underlying neoplastic disease.

\section{Discussion}

We report two new cases of NCSE as a complication of IFX chemotherapy. Both the EEG findings and the improvement following diazepam therapy indicated a diagnosis of NCSE. Vascular and metabolic etiologies were excluded on the basis of CT scan and biochemical profile and the time course of the encephalopathy with respect to IFX infusion suggested a causeand-effect relationship. Although the mechanism of IFX neurotoxicity has not been elucidated, there is some evidence that encephalopathy may be related to chloroacetaldehyde, an IFX metabolite whose neurotoxicity is due to its structural similarity with acetaldehyde, which is known to lower the seizure threshold by reducing the brain concentration of $\gamma$ aminobutyric acid. .-10 $^{-10}$

Risk factors for IFX neurotoxicity include high dosage and rapid infusion, renal and hepatic disfunction, low serum albumin, bulky pelvic disease, prior CNS disease, and previous treatment with cisplatin. ${ }^{1-3}$ Mild impairment of hepatic function and rapid infusion of IFX were present in both of our patients.

Continuous slow infusion of IFX is associated with a significant decrease in risk of encephalopathy as compared to bolus dosing. Moreover, the intravenous administration of methylene-blue has recently been suggested to prevent or rapidly reverse IFX neurotoxicity. ${ }^{11}$ Indeed no symptoms of neurotoxicity occurred when one of our patients was rechallenged with a further course of IFX associated with oral methylene-blue one month later.

The encephalopathy usually clears within three to four days (range 1-12 days) but persistent symptoms or even fatality may occur. Electroencephalogram abnormalities have often been 
described as exhibiting diffuse slow wave activity sometimes mixed with sharp waves. ${ }^{5-12}$ A correlation between EEG findings and degree of clinical impairment has been suggested and EEG may represent a marker of improvement. ${ }^{3-5}$

After searching the literature using MEDLINE, Current Contents and by reviewing reference lists, we found records of only six patients with an EEG pattern of NCSE in the acute stage of IFX encephalopathy; that is, within 24 hours from the onset of neurotoxicity symptoms (Table). Indeed, a definite diagnosis of IFX-related NCSE was established only for three of them, but clinical and EEG features of the reported cases suggest that NCSE was likely to have occurred in the other three patients as well.

Nonconvulsive status epilepticus is usually defined as a state lasting longer than one hour, characterized by slowness in behaviour and mentation, confusion and sometimes stupor (or coma), accompanied by generalized epileptiform continuous or nearly continuous activity in the form of spike waves, polyspike waves, or more complex discharges in the EEG. ${ }^{13}$ The diagnosis of NCSE may be further confirmed by a prompt effect of antiepileptic medication on both EEG and clinical manifestations but the intravenous administration of diazepam has sometimes been associated with increased mortality and morbidity in critically ill elderly patients, ${ }^{14}$ while other antiepileptic drugs such as phenobarbital can enhance IFX neurotoxicity. ${ }^{15}$ The regimen of low-dose diazepam, chosen to avoid harmful effects in severely ill patients, was associated with an improvement in both patients. Of course, no general inference on the impact of this treatment is warranted, since spontaneous recovery could have occurred as well.

The clinical presentation of NCSE is extremely variable: impaired spontaneous speech with verbal perseveration and monosyllabic answers are often the only symptoms, and many patients are often misdiagnosed with psychiatric disorders. Although no clinical feature is diagnostic of NCSE, it should be considered whenever a patient presents with an unexplained alteration of his or her mental state. Electroencephalogram is essential to warrant diagnosis and treatment, which should be as timely as possible since seizure duration and delay to diagnosis are determinants of increased mortality. ${ }^{16}$ Although IFX encephalopathy has been described, more recent evidence of a possible epileptic mechanism emphasises the importance of an early EEG evaluation, including a cautious evaluation of the response to benzodiazepine administration.

\section{REFERENCES}

1. Hammack JE, Cascino TL. Chemotherapy and other common druginduced toxicities of the central nervous system in patients with cancer. In: Vecht ChJ, ed. Handbook of Clinical Neurology, Vol. 25(69): Neuro-Oncology, Part III. Amsterdam: Elsevier Science B.V., 1997: 481-493.

2. Meanwell CA, Blake AE, Blackledge G, et al. Encephalopathy associated with ifosfamide/mesna therapy. Lancet 1985; 1: 406407.

3. Meanwell CA, Blake AE, Kelly KA, Honigsberger L, Blackledge G. Prediction of ifosfamide/mesna associated encephalopathy. Eur J Cancer Clin Oncol 1986; 22: 815-819.

4. Gieron A, Barak LS, Estrada J. Severe encephalopathy associated with ifosfamide administration in two children with metastatic tumors. J Neurooncol 1988; 6: 29-30.

5. Wengs WJ, Talwar D, Bernard J. Ifosfamide-induced nonconvulsive status epilepticus. Arch Neurol 1993; 50: 1104-1105.

6. Bhardwaj A, Badesha PS. Ifosfamide-induced nonconvulsive status epilepticus. Ann Pharmacother 1995; 29: 1237-1239.

7. Kaplan PW. Nonconvulsive status epilepticus in the emergency room. Epilepsia 1996; 37: 643-650.

8. Adde M, Shad A, Venzon D, et al. Additional chemotherapy agents improve treatment outcome for children and adults with advanced B-cell lymphomas. Semin Oncol 1998; 25: 33-39.

9. Simonian NA, Gilliam FG, Chiappa KH. Ifosfamide causes a diazepam-sensitive encephalopathy. Neurology 1993: 43: 27002702.

10. Homeida AM, Cooke RG. Anti-convulsant activity of diazepam and clonidine on metaldehyde-induced seizures in mice: effects on brain gamma-amino butyric acid concentrations and monoamine oxidase activity. J Vet Pharmacol Ther 1982; 5: 187-190

11. Kupfer A, Aeschlimann C, Wermuth B, Cerny T. Prophylaxis and reversal of ifosfamide encephalopathy with methylene-blue. Lancet 1994; 343: 763-764.

12. Danesh MM, De Giorgio CM, Beydoun SR, Kemp RA. Ifosfamide encephalopathy. J Toxicol Clin Toxicol 1989; 27: 293-298.

13. Guberman A, Cantu-Reyna G, Stuss D, Broughton R. Nonconvulsive generalized status epilepticus: clinical features, neuropsychological testing, and long-term follow-up. Neurology 1986; 36: 1284-1291.

14. Litt B, Wityk RJ, Hertz SH, et al. Nonconvulsive status epilepticus in the critically ill elderly. Epilepsia 1998; 39: 1194-1202.

15. Ghosn M, Carde P, Leclerq B, et al. Ifosfamide/mesna related encephalopathy: a case report with a possible role of phenobarbital in enhancing neurotoxicity. Bull Cancer 1988; 75: 391-392.

16. Young GB, Jordan KG, Doig GS. An assessment of nonconvulsive seizures in the intensive care unit using continuous EEG monitoring. An investigation of variables associated with mortality. Neurology 1996; 47: 83-89. 